\title{
Induction of Beet-Cyst Nematode Suppressiveness by the Fungi Dactylella oviparasitica and Fusarium oxysporum in Field Microplots
}

\author{
Rabiu Olatinwo, James Borneman, and J. Ole Becker
}

First and second authors: Department of Plant Pathology, University of California, Riverside 92521; and third author: Department of Nematology, University of California, Riverside 92521. Accepted for publication 13 March 2006.

\section{ABSTRACT}

Olatinwo, R., Borneman, J., and Becker, J. O. 2006. Induction of beetcyst nematode suppressiveness by the fungi Dactylella oviparasitica and Fusarium oxysporum in field microplots. Phytopathology 96:855-859.

The ability of Dactylella oviparasitica and Fusarium oxysporum to suppress Heterodera schachtii numbers was examined in field microplots. Fungi were individually added to fumigated field soil that was seeded with sugar beet. Four weeks later, soils were infested with $H$. schachtii second-stage juveniles (J2). At two harvests, 11 weeks and 19 weeks $\left(1,469\right.$ and 2,547 degree days (base $\left.8^{\circ} \mathrm{C}\right)$, respectively) after nematodeinfestation, $H$. schachtii cyst and egg numbers were assessed. At both time points, $D$. oviparasitica reduced $H$. schachtii population densities to those in the naturally suppressive soil, even when additional $H$. schachtii $\mathrm{J} 2$ were added to the microplots after the first harvest. Although $F$. oxysporum did not alter $H$. schachtii population densities after 11 weeks, significant reductions were detected after 19 weeks. The sustainability of the $H$. schachtii suppressiveness created by single applications of the fungi at the beginning of the microplot trials was further examined in a greenhouse study. Soil collected at the completion of the microplot trials was potted and seeded with sugar beet. Four weeks later, each pot was infested with $H$. schachtii J2. Approximately 16 weeks (1,389 degree days) after seeding, the $D$. oviparasitica-amended soil produced greater fresh root weights and considerably smaller nematode population densities than the nonamended control.
Soils suppressive to plant-parasitic nematodes do not allow significant population development of those nematodes despite conducive physical conditions and the presence of susceptible hosts. In some cases, nematode population densities initially increase and then decline and remain at low levels, typically below the economic damage threshold $(2,11)$. Nematode-suppressive soils are likely to occur worldwide, but only a limited number have been identified, and fewer have been studied in detail $(6,7,12,16)$. Given the complexity of soil microbial communities (9) and the methodological limitations of examining them (1), understanding the nature of nematode-suppressive soils remains a considerable challenge. The recent addition of molecular approaches, however, has assisted in identifying the causal agents of biologically suppressive soils $(10,19,25,26)$.

For a number of years, we have investigated a nematode-suppressive soil at field 9E, an approximately 2-ha site at the University of California-Riverside Agricultural Field Station $(8,20-$ 24). In 1975, field 9E was infested with the beet-cyst nematode (Heterodera schachtii) to test the efficacy of nematicides against this pest. The crops planted at this site, which were mostly hosts of $H$. schachtii, experienced severe disease and yield reductions during the first few years. In subsequent years, however, beet-cyst nematode population densities and disease incidence declined and have remained low for the last quarter of a century.

Biocidal treatments of this soil with various fumigants or heat followed by reinfestation with $H$. schachtii have demonstrated the biological nature of the $9 \mathrm{E}$ soil suppressiveness (20). Amendment of $1 \%$ of the $9 \mathrm{E}$ soil into a fumigated nonsuppressive $9 \mathrm{E}$ field site effectively transferred the suppressiveness (21), while exposure to $55^{\circ} \mathrm{C}$ for $30 \mathrm{~min}$ eliminated it (22). In addition, $H$. schachtii cysts that developed in the suppressive soil transferred the suppressive-

Corresponding author: J. O. Becker; E-mail address: obecker@ucr.edu

DOI: 10.1094/PHYTO-96-0855

(C) 2006 The American Phytopathological Society ness to fumigated nonsuppressive 9E soil (22). This demonstrated that the suppressive factors in the soil were biological in origin and present in the cysts, making subsequent investigations to identify these factors a more feasible task.

To identify the microorganisms involved in this $H$. schachtii suppressive soil, we employed a three-phased approach: (i) we identified microorganisms whose population levels correlated with the suppressiveness through extensive rRNA gene analysis; (ii) we validated the population trends with sequence-selective, quantitative polymerase chain reaction; and (iii) we reintroduced the microorganisms into the environment to assess their functions. This approach led to the identification of rRNA genes from two fungi (25) and one bacterium (26) that positively correlated with the $H$. schachtii suppressiveness. The fungi were isolated and tested in greenhouse trials (13). Both fungi were added to fumigated nonsuppressive soil, which was planted with Swiss chard and infested with $H$. schachtii second-stage juveniles (J2). Two nematode generations after infestation, Dactylella oviparasitica strain 50 reduced $H$. schachtii egg and juvenile numbers to those in the suppressive soil and $H$. schachtii cysts to levels lower than in the suppressive soil. In contrast, Fusarium oxysporum strain 471 did not significantly reduce $H$. schachtii population densities.

In this report, the abilities of $D$. oviparasitica strain 50 and $F$. oxysporum strain 471 to suppress $H$. schachtii population densities were evaluated in field microplot trials, of at least four nematode generations in duration. The sustainability of the $H$. schachtii suppressiveness created by single applications of the fungi at the beginning of the field microplot trials was examined in a follow-up greenhouse study.

\section{MATERIALS AND METHODS}

Fungi production. The isolation and identification of the fungi used in the study were previously described (13). Ten-centimeterdiameter petri plates containing potato dextrose agar (PDA) were inoculated with individual 5-mm-diameter agar plugs containing 
D. oviparasitica strain 50 or F. oxysporum strain 471 . These cultures were grown at room temperature for approximately 10 (F. oxysporum) and 21 (D. oviparasitica) days. After the incubation period, the fungal culture and PDA medium from each plate were transferred to a Sunbeam 6 Speed Blender (Model 4142, Sunbeam Products Inc., Boca Raton, FL) containing $50 \mathrm{ml}$ of sterile water. The components were blended for $30 \mathrm{~s}$ using the blend setting. One-half milliliter of each mixture was used to estimate the inoculum concentrations by determining the number of colony forming units (CFU) from a dilution series. The remaining portions of the fungal mixtures were added to soil (within $1 \mathrm{~h}$ of blending the fungi) as described below.

Field microplot experiment. Two replicate trials were conducted in the beet-cyst nematode-suppressive field 9E located at the University of California-Riverside Agricultural Research Station (20). The soil type was a Hanford fine sandy loam $(60.9 \%$ sand, 29.6\% silt, and 9.5\% clay, pH 8). In February 2004, the field soil was disked and leveled. Both microplot trials were set side-by-side, each in a randomized complete block design with seven treatments and eight replicates. Trial 1 was conducted from 1 April 2004 to 15 September 2004 and trial 2 from 7 April 2004 to 22 September 2004. The two trials were independently conducted and separated in time and space. Each setup consisted of 56 open-bottomed polyethylene 56 -liter pots $(\approx 25-\mathrm{cm}$ diameter $)$ inserted $45 \mathrm{~cm}$ into the ground. Two weeks before the start of the trials, the soil in the buried pots (microplots) was removed, sieved ( $\approx 6-\mathrm{mm}$ openings), and returned to the microplots. The microplots were filled to approximately $3 \mathrm{~cm}$ below the top to standardize the amount of soil. The soil in each microplot was fumigated with $2 \mathrm{ml}$ of methyl iodide $\left(\approx 690 \mathrm{~kg} \mathrm{ha}^{-1}\right)$ (3) and covered with plastic tarp (0.03-mm thick) for 4 days. Some microplots were not fumigated and are referred to as suppressive soil (or positive control) microplots. The four basic treatments were as follows: (i) D. oviparasitica strain 50, (ii) F. oxysporum strain 471, (iii) fumigated 9E soil (nonsuppressive control), and (iv) nonfumigated $9 \mathrm{E}$ soil (suppressive control). Three additional treatments, $\mathrm{v}$ to vii, included those identical to treatments i, iii, and iv, except that they received additional nematode inoculum after the first harvest (described in next paragraph). Fungal suspensions (described above) and fumigated soil from the top $10 \mathrm{~cm}$ of each microplot were thoroughly mixed in plastic bags and then returned to the microplots. For trial 1, fungal CFU per microplot were $3.0 \times 10^{6}$ (D. oviparasitica strain 50) and $9.0 \times 10^{8}(F$. oxysporum strain 471). For trial 2, fungal CFU per microplot were $2.8 \times 10^{6}$ (D. oviparasitica strain 50 ) and $8.2 \times 10^{9}$ (F. oxysporum strain 471). The microplots were seeded with sugar beet (Beta vulgaris cv. BETA 4430R, Betaseed Inc., Shakopee, MN) the same day. Four weeks later, plants were thinned to three per microplot and each microplot was infested with $H$. schachtii. An aqueous suspension of 7,000 freshly hatched $\mathrm{J} 2$ per plant was pipetted into three holes $(\approx 3.0-\mathrm{cm}$ deep and $1.5-\mathrm{cm}$ wide $)$ in the surface of the soil around each plant. The J2 inoculum was collected using a zinc chloride hatching protocol (14). Each microplot was fertilized with $6 \mathrm{~g}$ of slow-release fertilizer (Sierra 17-6-10 plus Minors, Scotts-Sierra Horticultural Products Company, Marysville, $\mathrm{OH})$. Microplots were watered with a low-volume drip irrigation system and the soil water potential was monitored with tensiometers. Soil daily minimum and maximum soil temperatures were monitored and recorded using HOBO Temp devices (Onset Computer Corporation, Bourne, MA) buried approximately $5 \mathrm{~cm}$ below the soil surface.

Eleven weeks after infestation with $H$. schachtii $(\approx 1,469$ degree days, base temperature of $8^{\circ} \mathrm{C}$ [4]), one plant per microplot was harvested and approximately $350 \mathrm{~cm}^{3}$ of soil was collected from around the plant. Adhering soil and cysts were shaken from the root systems and mixed into the corresponding soil sample. Fresh root and dry shoot weights were measured. Cysts were extracted from 350-g subsamples of the soil according to the modified
Fenwick flotation can method (5). Cysts were counted and then broken in a tissue homogenizer for egg counting. At this time, treatments $\mathrm{v}$ to vii were reinfested with an additional 7,000 $\mathrm{H}$. schachtii J2 per microplot. After an additional 8 weeks $(\approx 1,078$ degree days $)$, the experiment was ended; this was 19 weeks $(\approx 2,547$ degree days) after the initial infestation with nematodes. Nematode population densities and plant weights were assessed as described previously.

Greenhouse experiment. Two greenhouse trials were set up 1 week apart using the remaining soil from the field microplot trials. The objective of this study was to determine whether the $H$. schachtii suppressiveness created by D. oviparasitica strain 50 or F. oxysporum strain 471 in the field microplots could be sustained for another cropping cycle. A similar experimental design as that used for the field microplot trials was implemented in the greenhouse. Soil taken from each microplot replicate was emptied into separate plastic bags and thoroughly mixed before placing into corresponding $1,500-\mathrm{cm}^{3}$ pulp pots. The treatments were the same as those used in the field microplots except an additional fumigated 9E soil (nonsuppressive control) was added to provide a freshly fumigated control. No additional fungal inocula were added. The soils were seeded with five sugar beet seeds (cv. BETA 4430R) per pot. All pots were placed in a greenhouse under natural light at $23 \pm 3^{\circ} \mathrm{C}$ in a randomized complete block design with six replicates. Plants were watered as needed and soil temperature was monitored using HOBO Temp devices buried in an extra pot containing soil.

After emergence, the seedlings were thinned to one per pot and fertilized with $6 \mathrm{~g}$ of slow-release fertilizer (microplot experiment). Four weeks after seeding, designated treatments were additionally reinfested with approximately 7,000 $\mathrm{H}$. schachtii $\mathrm{J} 2$ as described previously. The greenhouse experiment was ended approximately 16 weeks $(\approx 1,389$ degree days) after seeding. Plant tops were cut off at soil level and roots were removed from soil. Fresh root and dry shoot weights were measured. Cysts were extracted from 350 -g subsamples of the soil according to the modified Fenwick flotation can method (5). Cysts were counted and then broken in a tissue homogenizer for egg counting. H. schachtii J2 were collected and enumerated using a zinc chloride hatching protocol (14).

Data analysis. Numbers of cysts, eggs, and $\mathrm{J} 2$ were $\log (x+1)$ transformed to normalize the data. The transformed cyst, egg, and $\mathrm{J} 2$ numbers, and the plant weights were subjected to analysis of variance and Student-Newman-Keuls tests (SAS Institute, Cary, NC).

\section{RESULTS}

Field microplot experiment. Two replicate field microplot trials were conducted to evaluate the ability of $D$. oviparasitica strain 50 and $F$. oxysporum strain 471 to suppress $H$. schachtii population densities. Because the results from both trials were similar, the data were combined for presentation with degree days averaged for each time point (Tables 1 and 2). At both sampling times (15 and 23 weeks after seeding), D. oviparasitica reduced $H$. schachtii egg and cyst numbers to those in the naturally suppressive soil (Tables 1 and 2), even when additional $H$. schachtii $\mathrm{J} 2 \mathrm{had}$ been added after approximately $60 \%$ of the season (Table 1). Although $F$. oxysporum did not alter $H$. schachtii population densities after 15 weeks, it reduced both egg and cyst numbers 23 weeks after seeding. No differences in fresh root and dry shoot weights were observed in the field microplot trials (data not shown).

Greenhouse experiment. The abilities of the soils from the completed field microplot trials to suppress $H$. schachtii population densities were assessed in a greenhouse experiment. Because the results from both trials of this experiment were similar, the data were combined for presentation. 
With or without additional H. schachtii infestation, D. oviparasitica reduced $H$. schachtii egg, cyst, and $\mathrm{J} 2$ numbers to those in the naturally suppressive soil (Table 2 ). Although an $F$. oxysporum treatment with additional $H$. schachtii infestation was not included, the fungus did reduce $H$. schachtii cysts but not egg or juvenile numbers compared with that of the nonsuppressive control (Table 2).

In treatments without the additional $H$. schachtii infestation, D. oviparasitica produced the highest fresh root weight and greater dry shoot weight than the suppressive soil control (Table 2 ). In the treatments with the additional $H$. schachtii infestation, there was no difference in plant weights among the treatments.

\section{DISCUSSION}

The results of this field microplot study combined with those from our previous investigations support our hypothesis that $D$. oviparasitica and $F$. oxysporum are key factors in the $H$. schachtii population suppressiveness exhibited by this southern Californian soil. Prior culture-based experimentation suggested that $D$. oviparasitica and $F$. oxysporum were common fungal inhabitants of $H$. schachtii cysts obtained from this soil (22). Molecular population studies showed that $D$. oviparasitica and $F$. oxysporum rRNA gene levels positively correlated with high and minimal to moderate levels of suppressiveness, respectively (25). Subsequent greenhouse experiments demonstrated that D. oviparasitica strain 50 reduced $H$. schachtii population densities to those in the naturally suppressive soil (13). In addition, the same greenhouse trials showed that $F$. oxysporum strain 471 did not significantly reduce $H$. schachtii population densities (13). However, the longer term microplot experiments from this current study suggested that $F$. oxysporum strain 471 can also suppress $H$. schachtii, but that this $F$. oxysporum strain requires more time than $D$. oviparasitica strain 50 to reduce nematode population levels. Furthermore, the effect of $F$. oxysporum strain 471 on $H$. schachtii populations appears to be shorter in duration than that of $D$. oviparasitica strain 50 , as the $F$. oxysporum-induced reductions in cyst and egg numbers observed at the termination of the microplot trials were not maintained in the follow-up greenhouse trials.

A notable result from this study was the ability of a single application of $D$. oviparasitica strain 50 to produce stable $H$. schachtii suppressiveness, at least for the duration of these experiments. In the field microplots, the single $D$. oviparasitica application at the beginning of the trials kept $H$. schachtii population densities low for the entire cropping season, which comprised at least four or five nematode generations. The follow-up greenhouse experiment demonstrated that this D. oviparasiticainduced suppressiveness was maintained for an additional cropping cycle and at least two more nematode generations. Moreover, this single application was also able to keep nematode population densities low over the entire study, including both the microplot and follow-up greenhouse experiments, even when the soils were subjected to three separate $H$. schachtii infestations. The successful introduction of $D$. oviparasitica might have been aided by the disturbance in the microbial composition following soil fumigation. However, as the amendment of $F$. oxysporum strain 471 has demonstrated, introduction of an $H$. schachtii-endoparasitic fungus into fumigated soil does not necessarily achieve suppressiveness. Further field studies will be needed to determine if amend-

TABLE 1. Heterodera schachtii population densities of sugar beets as affected by Dactylella oviparasitica and Fusarium oxysporum in field microplots 15 weeks and 23 weeks after seedingy

\begin{tabular}{|c|c|c|c|c|}
\hline \multirow[b]{2}{*}{ Treatment } & \multicolumn{2}{|c|}{ First harvest } & \multicolumn{2}{|c|}{ Second harvest } \\
\hline & Cysts per $350 \mathrm{~g}$ of soil & Eggs per $350 \mathrm{~g}$ of soil & Cysts per $350 \mathrm{~g}$ of soil & Eggs per $350 \mathrm{~g}$ of soil \\
\hline D. oviparasitica strain 50 & $196 \mathrm{~b}$ & $953 \mathrm{~b}$ & $203 c$ & $420 \mathrm{c}$ \\
\hline F. oxysporum strain 471 & $554 \mathrm{a}$ & $6,634 \mathrm{a}$ & $630 \mathrm{~b}$ & $2,044 \mathrm{~b}$ \\
\hline Nonfumigated 9E soil (suppressive control) & $162 \mathrm{~b}$ & $1,028 \mathrm{~b}$ & $182 \mathrm{c}$ & $365 \mathrm{c}$ \\
\hline D. oviparasitica strain $50+$ reinfestation ${ }^{\mathrm{z}}$ & $181 \mathrm{~b}$ & $804 \mathrm{~b}$ & $272 \mathrm{c}$ & $392 \mathrm{c}$ \\
\hline Fumigated 9E soil (nonsuppressive control) + reinfestation ${ }^{z}$ & 969 a & 15,034 a & $1,691 \mathrm{a}$ & $6,475 \mathrm{a}$ \\
\hline
\end{tabular}

y Fungi were added to fumigation-induced nonsuppressive soil in field microplots. All treatments were seeded with sugar beet, infested with second-stage juveniles (J2) of $H$. schachtii 4 weeks later, and assessed at two harvests 11 weeks (1,469 degree days) and 19 weeks (2,547 degree days) after the initial infestation with nematodes. Results from two trials were similar and were combined. Values are the means of 16 replicate microplots. Numbers of cysts and eggs were $\log (x+1)$ transformed to normalize the data. Means presented are based on nontransformed data. Means with the same letter are not significantly different $(P \geq 0.05)$.

${ }^{\mathrm{z}}$ Microplots receiving these treatments were reinfested with $H$. schachtii $\mathrm{J} 2$ after the first harvest $(1,469$ degree days). At the first harvest, these treatments were identical to those treatments with the same name minus the term reinfestation.

TABLE 2. Heterodera schachtii population densities and plant weights of sugar beets as affected by Dactylella oviparasitica and Fusarium oxysporum in followup greenhouse trials ${ }^{\mathrm{z}}$

\begin{tabular}{|c|c|c|c|c|c|}
\hline$\underline{\text { Treatment }}$ & $\begin{array}{l}\text { Fresh root } \\
\text { weight }(\mathrm{g})\end{array}$ & $\begin{array}{l}\text { Dry shoot } \\
\text { weight }(\mathrm{g})\end{array}$ & $\begin{array}{c}\text { Cysts per } \\
350 \mathrm{~g} \text { of soil }\end{array}$ & $\begin{array}{c}\text { Eggs per } \\
350 \mathrm{~g} \text { of soil }\end{array}$ & $\begin{array}{c}\mathrm{J} 2 \text { per } \\
350 \mathrm{~g} \text { of soil }\end{array}$ \\
\hline D. oviparasitica strain 50 & $70 \mathrm{a}$ & $14 \mathrm{a}$ & $152 \mathrm{c}$ & $529 \mathrm{~b}$ & $1,469 \mathrm{dc}$ \\
\hline F. oxysporum strain 471 & $40 \mathrm{bc}$ & $12 \mathrm{ab}$ & $563 \mathrm{~b}$ & 14,538 a & $14,465 \mathrm{ab}$ \\
\hline Fumigated 9E soil (nonsuppressive control) & $40 \mathrm{bc}$ & $11 \mathrm{ab}$ & $846 \mathrm{a}$ & $17,689 \mathrm{a}$ & $14,927 \mathrm{a}$ \\
\hline Nonfumigated 9E soil (suppressive control) & $28 \mathrm{c}$ & $10 \mathrm{~b}$ & $151 \mathrm{c}$ & $404 \mathrm{~b}$ & $934 \mathrm{~d}$ \\
\hline D. oviparasitica strain $50+$ reinfestation & $52 \mathrm{bc}$ & $12 \mathrm{ab}$ & $184 \mathrm{c}$ & $1,144 \mathrm{~b}$ & $1,244 \mathrm{dc}$ \\
\hline Fumigated 9E soil (nonsuppressive control) + reinfestation & $36 \mathrm{bc}$ & $10 \mathrm{~b}$ & $1,011 \mathrm{a}$ & $12,820 \mathrm{a}$ & $11,917 \mathrm{ab}$ \\
\hline Nonfumigated 9E soil (suppressive control) + reinfestation & $38 \mathrm{bc}$ & $11 \mathrm{ab}$ & $237 \mathrm{c}$ & $858 \mathrm{~b}$ & $5,378 \mathrm{bc}$ \\
\hline Fumigated 9E soil (nonsuppressive control) & $45 \mathrm{bc}$ & $12 \mathrm{ab}$ & $244 \mathrm{c}$ & $10,253 \mathrm{a}$ & 36,816 a \\
\hline
\end{tabular}

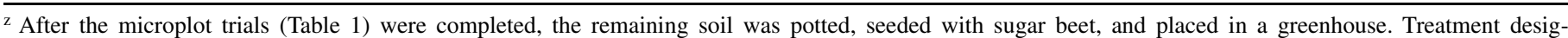
nations remained the same as in the microplots, but reinfested treatments received an additional 7,000 H. schachtii second-stage juveniles (J2) per pot 4 weeks after planting in the greenhouse. A recently fumigated soil was included as an additional nonsuppressive control. The experiment was ended 16 weeks after planting $(\approx 1,389$ degree days). Results from two trials were similar and were combined. Values are the means of 12 replicate pots. Numbers of cysts and eggs were $\log (x+1)$ transformed to normalize the data; means are based on nontransformed data, and means with the same letter are not significantly different $(P \geq 0.05)$. 
ment of D. oviparasitica to nonfumigated soil of various soil types result in similar nematode suppressiveness.

We propose that this stable $H$. schachtii population suppressiveness is associated with $D$. oviparasitica's ability to feed on and inhabit both the nematode and plant roots. While $D$. oviparasitica's ability to parasitize nematode eggs and developing adults contributes to the suppressiveness, its ability to inhabit $H$. schachtii's cysts enhances its long-term survival and the stability of the suppressiveness. In studies with Meloidogyne spp., D. oviparasitica parasitized living and dead eggs $(15,17,18)$ as well as females (18). In studies from our labs, both culture and culture-independent analyses have suggested that $D$. oviparasitica is one of the most abundant fungi in $H$. schachtii cysts from the suppressive $9 \mathrm{E}$ soil $(22,25)$. Application of D. oviparasitica strain 50 to nonsuppressive soil produced a high level of egg parasitism similar to the naturally suppressive 9E soil (13). If D. oviparasitica colonizes the rhizosphere and in particular the rhizoplane, it would provide a greater opportunity for the fungus to encounter and parasitize the nematode. This association would also provide the fungus with another source of nutrition and shelter, in the form of plant roots, which would last well beyond the end of the cropping cycle. Evidence for this fungus-root association comes from a Meloidogyne study that showed that $D$. oviparasitica can grow and sporulate on peach roots (15). Meloidogyne eggs in the rhizosphere were more likely to be parasitized by $D$. oviparasitica than those in soil, suggesting an increased presence or activity of this fungus near the roots (16). Another notable feature that should enhance $D$. oviparasitica's survival is its ability to parasitize eggs from several different nematodes species (18), providing it with a greater variety of potential food sources. Taken together, we suggest that all of these capabilities enable $D$. oviparasitica to be an effective $H$. schachtii parasite and facilitate its longterm survival, both of which are likely to be key elements in the creation and maintenance of stable nematode population suppressiveness.

One long-standing problem in studying the 9E suppressive soil has been determining whether an association exists between the H. schachtii population suppressiveness and plant growth parameters. In prior studies, differences in plant weights among soils with various levels of suppressiveness were frequently not detected $(8,20-22)$. In fact, if differences did exist, they were typically the opposite of what might be expected. That is, nonfumigated $9 \mathrm{E}$ soil possessing the natural $H$. schachtii population suppressiveness frequently produced lower plant weights than fumigated H. schachtii-reinfested 9E soil. One explanation for these data comes from the experimental approach used to create the less suppressive soils, which included various soil treatments such as soil fumigants, heat, and biocidal chemicals. We suggest the same treatments that reduced populations of the $H$. schachtii-suppresive microorganisms also reduced other plant-deleterious microorganisms, and that these other organisms, alone or in combination with the nematodes, had a greater impact on plant growth parameters than $H$. schachtii.

The discovery of fungi that appear to play key roles in this $9 \mathrm{E}$ suppressive soil has provided a better opportunity to examine the relationship between the $H$. schachtii population suppressiveness and plant growth parameters. It has allowed us to compare soils with the same abiotic characteristics but that differ in the microorganisms added to them. In the first of these experiments, D. oviparasitica strain 50 and $F$. oxysporum strain 471 were added to nonsuppressive soil in greenhouse trials (13). After two nematode generations, $H$. schachtii population densities and plant weights were assessed. Although significant differences in $H$. schachtii population densities were detected between the $D$. oviparasitica treatment and the nonamended control, no differences in plant weights were observed (13). We hypothesize that the lack of association between the $H$. schachtii population suppressiveness and plant weights in these studies was due to several factors including (i) the high initial nematode pressure under which the young host plants were grown, (ii) the relatively short duration of the experiments and, (iii) D. oviparasitica's likely primary mode of action, egg parasitism $(13,16-18)$. If this were correct, then considerable crop damage would have been done by the time the $H$. schachtii population-regulating forces of the biological agent(s) took effect. Using a similar line of reasoning, we suspected that the effect of the $H$. schachtii population suppressiveness on plant weights should be more apparent in longer term trials with multiple crop cycles. The data from the greenhouse phase of the study described in this report support this hypothesis, as the greatest root weights were obtained in $D$. oviparasiticaamended soil. Further studies will be needed to confirm this hypothesis.

\section{ACKNOWLEDGMENTS}

We thank J. Darsow for technical assistance. This project was supported by the National Research Initiative of the USDA Cooperative State Research, Education and Extension Service grant no. 2003-3531613824 .

\section{LITERATURE CITED}

1. Amann, R. I., Ludwig, W., and Schleifer, K. H. 1995. Phylogenetic identification and in situ detection of individual microbial cells without cultivation. Microbiol. Rev. 59:143-169.

2. Baker, K. F., and Cook, R. J. 1974. Biological Control of Plant Pathogens. W.H. Freeman, San Francisco.

3. Becker, J. O., Ohr, H. D., Grech, N. M., and Sims, M. E. 1998. Evaluation of methyl iodide as a soil fumigant in container and small field plot studies. Pestic. Sci. 52:58-62.

4. Caswell, E. P., and Thomason, I. J. 1991. A model of egg production by Heterodera schachtii (Nematoda: Heteroderidae). Can. J. Zool. 69:2085-2088.

5. Caswell, E. P., Thomason, I. J., and McKinney, H. E. 1985. Extraction of cysts and eggs of Heterodera schachtii from soil with an assessment of extraction efficiency. J. Nematol. 17:337-340.

6. Chen, S. Y., and Dickson, D. W. 1998. Review of Pasteuria penetrans: Biology, ecology, and biological control potential. J. Nematol. 30:313340 .

7. Crump, D. H. 1989. Interaction of cyst nematodes with their natural antagonists. Aspects Appl. Biol. 22:135-140.

8. Gao, X., and Becker, J. O. 2002. Population development of both sexes of Heterodera schachtii is diminished in a beet cyst nematode-suppressive soil. Biol. Control 25:187-194.

9. Hawksworth, D. L. 1991. The fungal dimension of biodiversity: Magnitude, significance, and conservation. Mycol. Res. 95:641-655.

10. Hirsch, P. R., Atkins, S. D., Mauchline, T. H., Morton, C. O., Davies, K. G., and Kerry, B. R. 2001. Methods for studying the nematophagous fungus Verticillium chlamydosporium in the root environment. Plant Soil 232:21-30.

11. Kerry, B. R. 1987. Biological control. Pages 233-263 in: Principles and Practice of Nematode Control in Crops. R. H. Brown and B. R. Kerry, eds. Academic Press, New York.

12. Kerry, B. R. 1988. Fungal parasites of cyst nematodes. Agric. Ecosyst. Environ. 24:293-305.

13. Olatinwo, R. O., Yin, B., Becker, J. O., and Borneman, J. 2006. Suppression of the plant-parasitic nematode Heterodera schachtii by the fungus Dactylella oviparasitica. Phytopathology 96:111-114.

14. Shepherd, A. M. 1970. Extraction and estimation of Heterodera. Pages 23-33 in: Laboratory Methods for Work with Plant and Soil Nematodes. J. F. Southey, ed. Her Majesty's Stationery Office, London.

15. Stirling, G. R. 1979. Techniques for detecting Dactylella oviparasitica and evaluating its significance in field soils. J. Nematol. 11:99-100.

16. Stirling, G. R. 1991. Biological Control of Plant Parasitic Nematodes. CAB International, Wallingford, UK.

17. Stirling, G. R., and Mankau, R. 1978. Dactylella oviparasitica, a new fungal parasite of Meloidogyne eggs. Mycologia 70:774-783.

18. Stirling, G. R., and Mankau, R. 1979. Mode of parasitism of Meloidogyne and other nematode eggs by Dactylella oviparasitica. J. Nematol. 11: 282-288.

19. Weller, D. M., Raaijmakers, J. M., McSpadden Gardener, B. B., and Thomashow, L. S. 2002. Microbial populations responsible for specific soil suppressiveness to plant pathogens. Annu. Rev. Phytopathol. 40: 309-348. 
20. Westphal, A., and Becker, J. O. 1999. Biological suppression and natural population decline of Heterodera schachtii in a California field. Phytopathology 89:434-440.

21. Westphal, A., and Becker, J. O. 2000. Transfer of biological soil suppressiveness against Heterodera schachtii. Phytopathology 90:401-406.

22. Westphal, A., and Becker, J. O. 2001. Components of soil suppressiveness against Heterodera schachtii. Soil Biol. Biochem. 33:9-16.

23. Westphal, A., and Becker, J. O. 2001. Impact of soil suppressiveness on various population densities of Heterodera schachtii. Ann. Appl. Biol. 138:371-376.
24. Westphal, A., and Becker, J. O. 2001. Soil suppressiveness to Heterodera schachtii under different cropping sequences. Nematology 3:551-558.

25. Yin, B., Valinsky, L., Gao, X., Becker, J. O., and Borneman, J. 2003. Identification of fungal rDNA associated with soil suppressiveness against Heterodera schachtii using oligonucleotide fingerprinting. Phytopathology 93:1006-1013.

26. Yin, B., Valinsky, L., Gao, X., Becker, J. O., and Borneman, J. 2003. Bacterial rDNA associated with soil suppressiveness against the plantparasitic nematode Heterodera schachtii. Appl. Environ. Microbiol. 69:1573-1580 